\title{
Increased $\alpha$-fetoprotein concentration in association with ileal adenocarcinoma complicating Crohn's
} disease

\author{
M LEADER, JR JASS \\ From the Department of Histopathology, Westminster Hospital, London SWIP 2AR
}

SUMMARY A considerably raised serum $\alpha$-fetoprotein concentration was found in a patient with an ileal adenocarcinoma. $\alpha$-fetoprotein was shown in both the primary tumour and the hepatic metastases by an immunoperoxidase technique. A raised $\alpha$-fetoprotein concentration in association with ileal adenocarcinoma has not been described previously, and it is notable that the first such case should occur as a complication of longstanding Crohn's disease.

$\alpha$-fetoprotein is a normal product of fetal liver and yolk sac. Small amounts may also be found in fetal gut.' ${ }^{\prime}$ A raised serum $\alpha$-fetoprotein concentration has been described in a variety of conditions, but concentrations above $1000 \mathrm{Ku} / \mathrm{l}$ are unusual in all but primary hepatocellular carcinomas and germ cell tumours. ${ }^{2}$ We have found a considerably increased concentration in association with an ileal-adenocarcinoma. Interestingly, the tumour arose as a complication of longstanding Crohn's disease.

\section{Case report}

A 30 year old man with a 15 year history of Crohn's disease presented with severe colicky abdominal pain. He had previously had several episodes of subacute intestinal obstruction, some of which necessitated admission to hospital. Each had responded to medical management. He had been maintained on low dosage prednisone for 13 years and intermittent azathioprine over the preceeding four years.

On this occasion the clinical findings included those of small bowel obstruction, which responded to conservative treatment. But a new finding of gross hepatomegaly was also noted. Liver function tests showed a serum bilirubin concentration of $70 \mu \mathrm{mol} / \mathrm{l}$, aspartate transferase $69 \mathrm{IU} / \mathrm{l}$, alanine transferase $41 \mathrm{IU} / \mathrm{l}$, and alkaline phosphatase $1500 \mathrm{IU} / \mathrm{l}$. Ultrasound confirmed hepatomegaly and showed multiple echogenic areas consistent with metastases. A computed tomogram confirmed this impression.
A barium enema was essentially normal; a small bowel meal was not carried out.

$\alpha$-fetoprotein estimation by radioimmunoassay (using a double antibody technique with polyethylene glycol assisted precipitation) showed an initial value of $8612 \mathrm{Ku} / \mathrm{l}$ which quickly rose to $15540 \mathrm{Ku} / \mathrm{l}$ (normal less than $10 \mathrm{Ku} / \mathrm{l}$ ). A diagnosis of a primary hepatocellular carcinoma or a germ cell tumour was therefore considered, but the testes were normal and there was no previous history of liver impairment. Carcinoembryonic antigen concentration was also raised at $963 \mu \mathrm{g} / \mathrm{l}$ (normal less than $10 \mu \mathrm{g} / \mathrm{l}$ ) but $\beta$-human chorionic gonadotrophin was within the normal range.

A liver biopsy showed widespread infiltration by a moderately differentiated mucin producing adenocarcinoma. As mucin production is not a feature of primary hepatocellular carcinoma, this diagnosis, despite the high $\alpha$-fetoprotein concentration, was discounted and a primary tumour of gastrointestinal origin was suggested. The patient deteriorated and died one week later.

\section{POSTMORTEM FINDINGS}

The salient features at necropsy concerned the liver and small intestine. The liver weighed $7710 \mathrm{~g}$ and $80 \%$ was replaced by white tumour deposits. The intervening parenchyma showed no evidence of cirrhosis. The lymph nodes at the porta hepatis were not enlarged. The large intestine was normal, but both the jejunum and ileum showed patchy involvement of Crohn's disease. The bowel wall was thickened and rigid and narrowed by multiple strictures (Fig. 1). The mucosal surface was roughened 


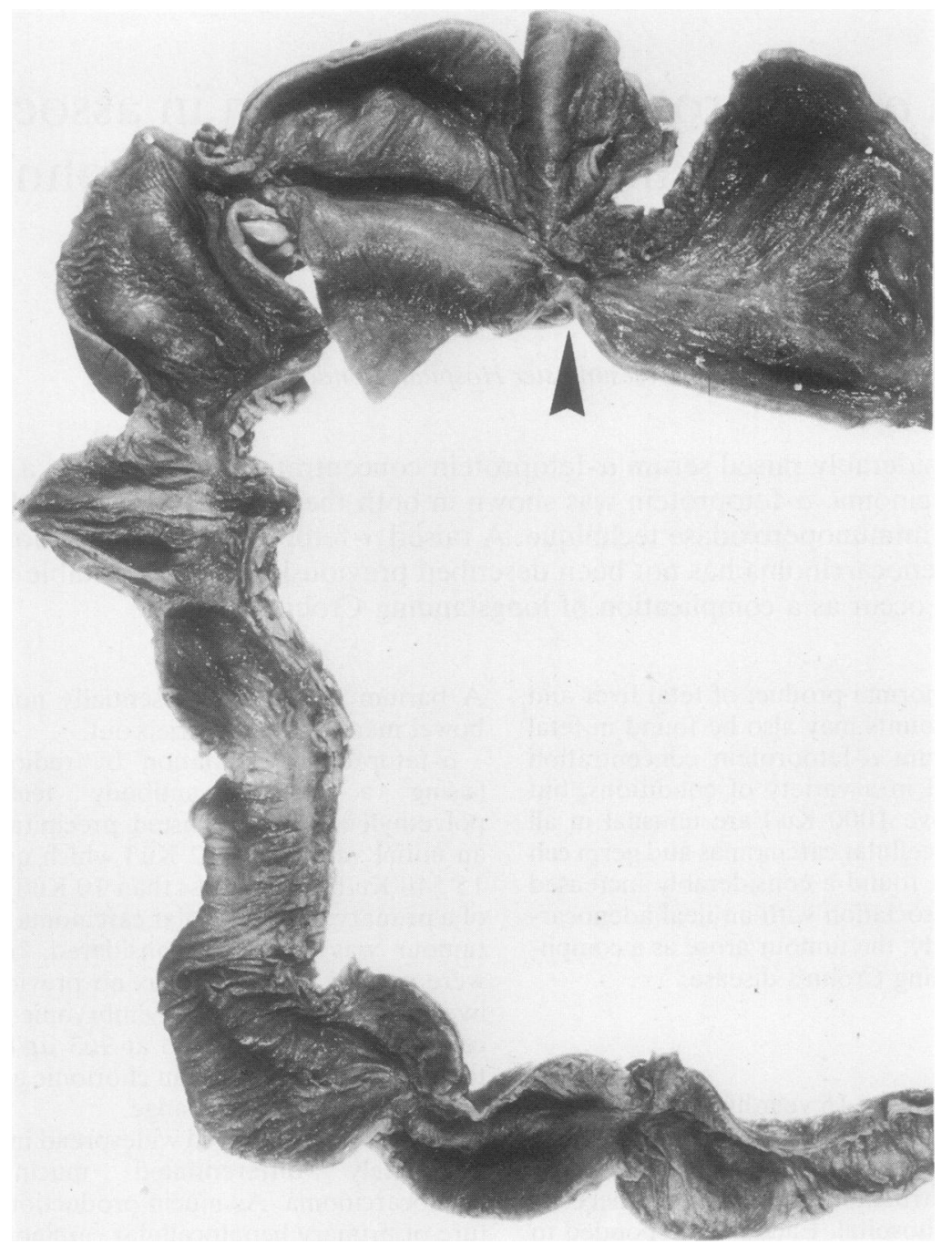

Fig. 1 Segment of distal ileum showing narrowing of the lumen by multiple strictures. Arrowhead points to the stricture from which the carcinoma is arising Magnification $\times 0.33$.

and granular and several inflammatory polyps projected into the lumen. Arising from one of the strictures in the distal ileum was a tumour measuring 5 $\mathrm{cm}$ in diameter (Fig. 1).

Histology confirmed the diagnosis of Crohn's disease. The mucosa was inflamed and showed patchy ulceration with occasional fissure formation. The mucus content of the glands was not depleted. The inflammatory polyps were composed of granulation tissue. Granulomas were not seen but pyloric type metaplasia of the glands was evident in the inflamed mucosa, the inflammatory polyps, and in the mucosa adjacent to the tumour (Fig. 2). The pyloric glands stained red with alcian blue/periodic acid Schiffdiastase, indicating the secretion of neutral mucins. The submucosa was oedematous and inflamed and showed an increase in fibrous tissue. It also contained rather prominent nerve trunks and collections of ganglion cells.

Histological examination of the tumour showed a moderately to poorly differentiated mucus producing adenocarcinoma, with a well marked glandular pattern in addition to more solid clumps of infiltrating cells (Fig. 3). Large sheets of tumour invaded 


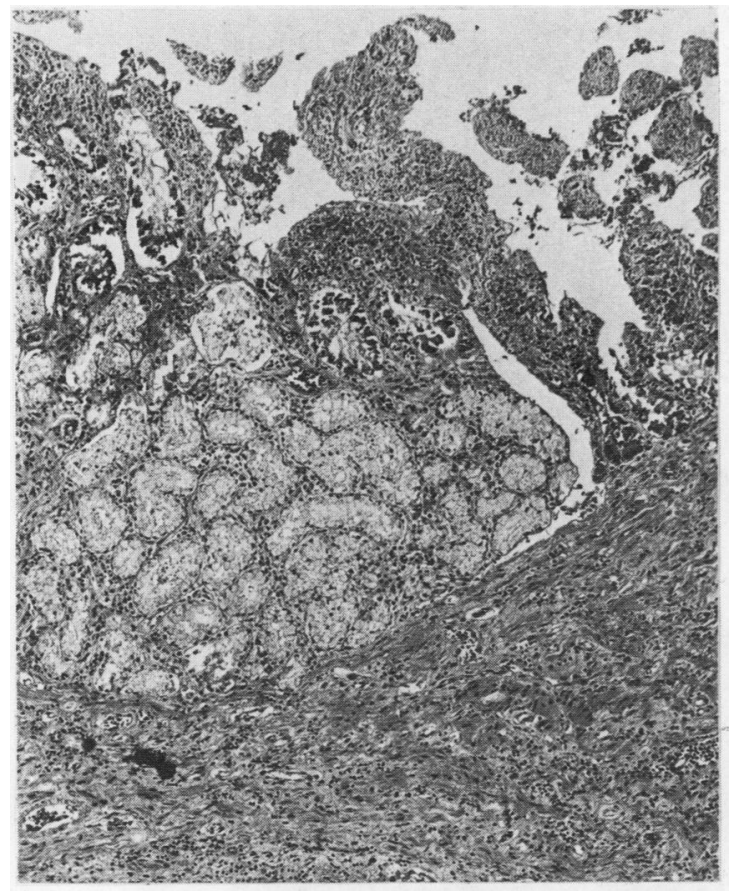

Fig. 2 Pyloric metaplasia of the glands adjacent to the carcinoma. The submucosa is also inflamed and fibrosed. Haematoxylin and eosin. Original magnification $\times 16$.

through the muscularis propria to reach the serosa. The pattern of infiltration did not resemble the "endometriotic like" invasion which is considered typical of Crohn's carcinoma. The tumour secreted neutral mucins only.

Liver histology showed a mucus producing adenocarcinoma similar to that in the ileum, and despite extensive sampling there was no evidence of a hepatocellular carcinoma.

\section{Immunohistochemistry}

Formalin fixed paraffin embedded tissue from the primary small bowel carcinoma and from the liver metastases were tested for $\alpha$-fetoprotein using the unlabelled (peroxidase-antiperoxidase) technique. Rabbit antihuman serum (Dako) was used at a dilution of $1 / 50$. Tumour from both sites showed positive granular staining of the cytoplasm of the tumour cells (Fig. 3). With a similar technique, the primary small bowel carcinoma and the liver metastases were positive for carcinoembryonic antigen. Rabbit antihuman CEA (Dako) was used at a dilution of $1 / 100$.

\section{Discussion}

Abelev $e^{2} a^{3}$ found the alpha globulin $\alpha$-fetoprotein in mice in 1963. It is found in low concentrations in the serum of normal adults $(5-10 \mathrm{Ku} / \mathrm{l})$ and small rises occur in pregnancy. $\alpha$-fetoprotein was initially thought to be a specific tumour marker of primary hepatocellular carcinoma, but with the advent of more sensitive radioimmunoassay techniques small rises in $\alpha$-fetoprotein concentration were discovered in a variety of non-neoplastic liver diseases and tumours of the gastrointestinal tract, ${ }^{4}$ lungs, ${ }^{5}$ and prostate. ${ }^{67}$ Slightly increased concentrations have been described in association with carcinoma of the stomach, pancreas, biliary tree, and less commonly the colorectum. ${ }^{489}$ Ruoslahti et al ${ }^{10}$ reported a rise of $>4000 \mathrm{Ku} / 1$ in a case of primary gastric carcinoma, and two papers report increased $\alpha$-fetoprotein concentrations in patients with dual primary carcinomas of the stomach and prostate. ${ }^{89}$ Five cases of gastric carcinoma with liver metastases are reported in the French published work ${ }^{113}$ but values of $\alpha$-fetoprotein are not given.

Increases in $\alpha$-fetoprotein concentration to $>100$ times normal are exceedingly rare in gastrointestinal tract malignancies. McIntire $e t a^{4}$ report four such cases: one a colorectal carcinoma with a value of $50000 \mathrm{Ku} / \mathrm{l}$, and two cases of gastric carcinoma and one of a pancreatic carcinoma with values less than $10000 \mathrm{Ku} / \mathrm{l}$.

The occurrence of small bowel carcinomas in Crohn's disease was first described by Ginzburg $e t$ al. ${ }^{14}$ Over 60 such cases have now been reported, ${ }^{15} 16$ and Weedon et $\mathrm{al}^{17}$ and Greenstein et $\mathrm{al}^{18}$ found the increased incidence of small bowel carcinoma in this group to be significant. None of the reports of small bowel cancer have given $\alpha$-fetoprotein values and the very high level in the case described here appears unique.

It is interesting to ask why a raised $\alpha$-fetoprotein concentration should be associated with ileal adenocarcinoma complicating Crohn's disease. $\alpha$-fetoprotein is a normal product of fetal liver and yolk sac, and small amounts may also be found in the gastrointestinal tract.' It is well known that the principal gastrointestinal malignancies associated with a raised $\alpha$-fetoprotein are those of the biliary system, stomach, and pancreas. ${ }^{19}$ Taken in conjunction with the liver, it would appear that malignancies of structures derived from the foregut show a particular association with $\alpha$-fetoprotein production. Crohn's disease is often associated with foregut or more specifically pyloric metaplasia. This was noted in the present case, and, in addition, the adenocarcinoma showed certain morphological and histochemical similarities to gastric carcinomas of 


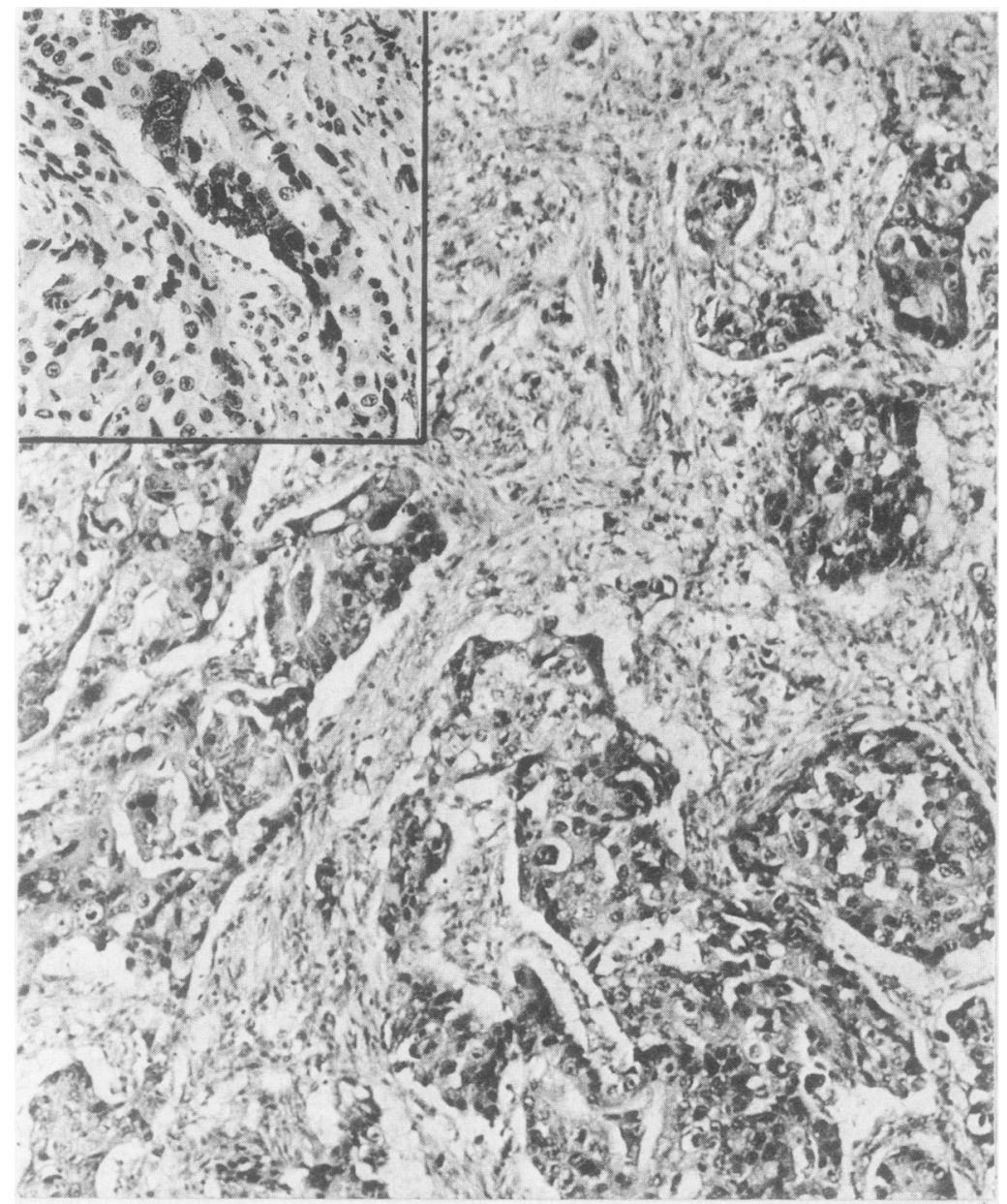

Fig. 3 Adenocarcinoma arising in the ileum showing glandular differentiation. The glands are lined by columnar cells with pale to acidophilic cytoplasm and small round nuclei tending to remain in the lower half of the cell. The architectural, cytological, and histochemical features of the tumour recall the pylocardiac type gastric carcinoma (see text). Inset shows positive staining of the tumour cells with $\alpha$-fetoprotein. Haematoxylin and eosin. Original magnification $\times 16$. Inset: Original magnification $\times 40$.

pylorocardiac type..$^{20}$ Foregut metaplasia could possibly be linked to the production of $\alpha$-fetoprotein by the present case, but further examples of this phenomenon must be sought and studied.

We thank Miss Michelle Brooks and Miss Teresa Godden for typing this paper. We are grateful to $\mathrm{Mr}$ $M$ Nelson for his photographic assistance. We also thank Dr Brian Gazzard, who looked after this patient.

\section{References}

' Gitlin D. Sites of alpha fetoprotein synthesis. $N$ Engl J Med 1971;285:1436-7.

${ }^{2}$ Sell S. Diagnostic application of alpha-fetoprotein. Government regulations prevent full application of a clinically useful test. Hum Pathol 1981;12:959-63.

${ }^{3}$ Abelev GI, Perova SD, Khramkova NI. Production of embryonal alpha globulin by transplantable mouse hepatomas. Transplantation 1963;1:174-86.

${ }^{4}$ McIntire KR, Waldmann TA, Moertel CG. Serum alphafetoprotein in patients with neoplasms of the gastrointestinal tract. Cancer Res 1975;35:991-6. 
s Tsung S. Alpha-fetoprotein in lung cancer metastatic to the liver. Arch Pathol 1975;99:267-9.

- Mehlman DJ, Bulkley BH, Wiernik PH. Serum alphafetoprotein in gastric and prostatic carcinomas. $N$ Engl $J$ Med 1971;285: 1060-1.

${ }^{7}$ Kozower M, Fawaz KA, Miller H. Positive alpha-fetoprotein in a case of gastic carcinoma. $N$ Engl J Med 1971;285:1059-60.

* Montplaisir S, Rabin B, Pelletier B. Alpha-fetoprotein content of gastric carcinoma and hepatic metastases. Am J Dig Dis 1973: 18:416-8.

' Bierfeld J, Scheiner M, Schultz D. Alpha-fetoprotein and carcinoembryonic antigen in a case of gastric carcinoma metastatic to the liver. Am J Dig Dis 1973:18:517-20.

${ }^{10}$ Ruoslahti E, Seppala M, Vuopio P. Radioimmunoassay of alpha-fetoprotein in primary and secondary cancer of the liver. $J$ Natl Cancer Inst 1972;49:623-8.

" Bourreile J, Metayer P, Sauger F. Existence d' alpha-fetoproteine au cours d'un cancer secondaire du foie d'origine gastrique. Presse Med 1970;78: 1277-8.

12 Geoffroy Y, Metayer P, Denis P. Alpha-fetoprotein et cancer secondaire du foie. Presse Med 1970;78:1896.

${ }^{13}$ Bernades P, Smadja M, Rueff B, et al. Presence de Palphafetoproteine serique dans quatre cas de cancers digestifs primitifs autre que l'hepatome. Presse Med 1971;7911:15857.
${ }^{14}$ Ginzburg L, Schneider KM, Dreizin DH, et al. Carcinoma of the jejunum occurring in a case of regional enteritis. Surgery 1956;39:347-51.

is Lightdale CJ, Sternberg SS, Posner G, et al. Carcinoma complicating Crohn's Disease Report of seven cases and review of literature. Am J Med 1975;59:262-8.

${ }^{16}$ Savage RA, Farmer RG, Hawk WA. Carcinoma of the small intestine associated with transmural ileitis (Crohn's Disease) Am J Clin Pathol 1975;63:168-78.

17 Weedon DD, Shorter RG, Illstrup DM, et al. Crohn's disease and cancer. N Engl J Med 1973;289: 1099-103.

is Greenstein AJ, Sachar DB, Smith H, et al. A comparison of cancer risk in Crohn's disease and ulcerative colitis. Cancer 1981;48:2742-5.

${ }^{19}$ Neville AM, Cooper EH. Biochemical monitoring of cancer. A review. Ann Clin Biochem 1976;13:283-305.

${ }^{20}$ Mulligan RM, Rember RR. Histogenesis and biologic behaviour of gastric carcinoma. Arch Pathol 1954;58:1-25.

Requests for reprints to: Dr Mary Leader, Department of Histopathology, The Westminster Hospital, London SW1P 2AR, England. 